\title{
A study on management, morbidity and mortality of ectopic pregnancy attending a tertiary care centre at Rajiv Gandhi Institute of Medical Sciences General Hospital, Kadapa, Andhra Pradesh, India
}

\section{T. Lakshmi Suseela*, Kesava Chandra Gunakala}

Department of Obstetrics and Gynecology, Rajiv Gandhi Institute of Medical Sciences, Kadapa, Andhra Pradesh, India

Received: 21 September 2016

Accepted: 26 September 2016

\section{* Correspondence:}

Dr. T. Lakshmi Suseela,

E-mail: thesisusm@gmail.com

Copyright: () the author(s), publisher and licensee Medip Academy. This is an open-access article distributed under the terms of the Creative Commons Attribution Non-Commercial License, which permits unrestricted non-commercial use, distribution, and reproduction in any medium, provided the original work is properly cited.

\section{ABSTRACT}

Background: Ectopic pregnancy is one of the life threatening condition, and catastrophic. It is commonest acute abdominal emergency in practice. The aim of the study was to study the management modalities and their outcome, morbidity and mortality in women with ectopic pregnancy.

Methods: This prospective study conducted in the Department of Obstetrics and Gynaecology at RIMS General Hospital, Kadapa for a period of 2 years. 50 cases of ectopic pregnancy were diagnosed and recruited for the study. TVS / TAS was done to diagnose and also to ascertain the severity of the condition. Apart from routine surgical profile, $\beta$-hCG assay was also performed.

Results: Out of 50 patients, 45 (98\%) patients were managed by laparotomy, 4 patients were by laparoscopically, one patient was successfully managed by medical therapy. The most common site for ectopic was found in ampulla in 32 $(68 \%)$ patients, followed by isthmus $6(12.24 \%)$, ovary $5(10.2 \%)$, interstitial $1(2.04 \%)$, cornua $2(4.08 \%)$, fimbria 1 $(2.04 \%)$ and infundibulam $2(4.08 \%)$. In our study group about morbidity, 48 cases post operative period was uneventful, 2 (4\%) cases were admitted in ICU.

Conclusions: Early diagnosis of ectopic pregnancy and prompt conservative surgical or medical management is needed to reduces maternal morbidity and mortality and also helps in preserving fertility.

Keywords: Ectopic pregnancy, Maternal morbidity and mortality, Salpingectomy

\section{INTRODUCTION}

Ectopic pregnancy is life threatening condition, and catastrophic and one of the commonest acute abdominal emergency in day to day practice. It has been recognized for over 400 years and continues to be an increasing affliction affecting approximately $2 \%$ of all pregnancies. It remains as an important contributor to maternal morbidity and mortality and one of the commonest causes of first trimester maternal death. ${ }^{1}$

Women affected with ectopic pregnancy are not only exposed to complications from the ectopic pregnancy and the related treatment procedures, but are also at a greater risk of another ectopic pregnancy, and future reproductive challenges can be distressing.

Over subsequent years, the advent of new diagnostic techniques, blood transfusions aseptic precautions, antibiotics, anaesthesia combined to save the lives of many women. Still late diagnosis and interventions are common. Now with recent advances the attention is shifted from saving lives to preserving fertility.

Many improvements were done to diagnose and treat ectopic pregnancies, to limit its impact on women's 
health. The concept of "discriminatory cutoff" of $\beta$-hCG was developed in 1985 for the diagnosis and management of suspected ectopic pregnancies by medical and conservative surgical procedures to make the women eligible for future fertility. ${ }^{2}$ It is defined as, the level of $\beta$ hCG at which a normal intrauterine pregnancy can be visualized by ultrasonography with sensitivity of $100 \%{ }^{2}$ It is widely accepted that, above the discriminatory zone of $1,500 \mathrm{mIU} / \mathrm{mL}-2,500 \mathrm{mIU} / \mathrm{mL}$, a normal intrauterine pregnancy should be visible by TVS. The absence of which implies abnormal gestation. ${ }^{3}$

Laparoscopy is the gold standard for diagnosing ectopic pregnancy and also it is possible to do conservative surgical procedures with less morbidity. ${ }^{4,5}$

Methotrexate, the first successfully used drug in clinical practice for un-ruptured ectopic pregnancy which is a folic acid antagonist. In 1985 Chotiner was the first in English literature to describe a patient with tubal pregnancy treated successfully with systemic methotrexate. ${ }^{6}$

To study the management modalities and their outcome, morbidity and mortality in women with ectopic pregnancy.

\section{METHODS}

\section{Source of study}

This is a prospective study conducted in the Department of Obstetrics and Gynaecology, RIMS General Hospital, Kadapa for a period of 2 years (June 2014-June 2016).

50 cases of ectopic pregnancy were diagnosed and recruited for the study after taking their consent for participation.

\section{Inclusion criteria}

All the cases diagnosed as ectopic pregnancy admitted to RIMS General hospital, KADAPA, during the study period of 2 years.

\section{Exclusion criteria}

It includes all intrauterine pregnancies.

\section{Patient analysis}

- Detailed history was taken.

- General, systemic, abdominal and vaginal examinations were done.

- Informed consent was taken and data were recorded on the Proforma.

- TVS / TAS was done to diagnose and to know the severity of the condition.
- Apart from routine surgical profile, $\beta-\mathrm{hCG}$ assay, UPT, coagulation profile, renal function tests, liver function tests were done.

- Patients were treated by different treatment modalities based on their hemodynamic stability.

- The diagnosis of ectopic pregnancy was confirmed by histo-pathological examination of the specimen after surgery.

- The morbidity and mortality associated with ectopic pregnancy was assessed.

\section{Serum $\beta$-hCG assay}

Modern assays for the $\beta$-subunit of hCG are highly sensitive and specific, with detection levels below 5 $\mathrm{mIU} / \mathrm{mL}$.

\section{Ultrasound}

\section{Transabdominal USG}

In transabdominal USG, intrauterine gestational sac should appear when the serum hCG levels are 6000 $6500 \mathrm{mIU} / \mathrm{mL}$. The absence of an apparent intrauterine sac with hCG levels at or above $6000 \mathrm{mIU} / \mathrm{mL}$ suggests an abnormal pregnancy, either ectopic or spontaneous abortion.

\section{Transvaginal USG}

Transvaginal USG is superior to transabdominal USG in diagnosing ectopic pregnancy. A 3-5 MHz transvaginal transducer allows for a deeper penetration of the pelvis than transducers of higher frequency, whereas a 7.5 MHz transvaginal transducer provides better near-resolution at the cost of shallower penetration.

\section{Statistical analysis}

- Data was collected and tabulated as shown in results.

- Statistical analysis was done using Microsoft Excel.

- Frequency and percentage of each parameter was calculated and analysed.

\section{RESULTS}

In the present study 50 patients with ectopic pregnancy were recruited, management and outcome were analysed. In the present study group of 50 patients, 45 (98\%) patients were managed by laparotomy, 4 patients were by laparoscopically and one patient was successfully managed by medical therapy. In the present study group, one patient with unruptured ectopic was planned for medical therapy. She was treated with single dose therapy.

\section{Operative findings}

In our study group, 25 patients had less than $1000 \mathrm{ml}$ of hemoperitoneum, 20 patients had hemoperitoeum of 
$1000-2000 \mathrm{ml}$ and 4 patients had $>2000 \mathrm{ml}$ of hemoperitoneum intra-operatively.

Regarding side of ectopic, 49 patients were underwent surgical treatment of this $51.02 \%$ (25) patients had ectopic pregnancy on right side and $46.8 \%$ (24) had ectopic pregnancy on left side.

Table 1: Ectopic pregnancy-management.

\begin{tabular}{|lll|}
\hline Management & Number (total of 50 cases) & $\%$ \\
\hline Laparotomy & 45 & $90 \%$ \\
\hline Laparoscopy & 4 & $8 \%$ \\
\hline Medical & 1 & $2 \%$ \\
\hline
\end{tabular}

In the present study group, 49 patients were successfully managed by surgical management. 1 patient with tubal pregnancy was successfully treated by medical therapy.

The most common site for ectopic was found in ampulla in $32(68 \%)$ patients, followed by isthmus $6(12.24 \%)$, ovary $5(10.2 \%)$, interstitial $1(2.04 \%)$, cornua $2(4.08 \%)$, fimbria $1(2.04 \%)$, infundibulam $2(4.08 \%)$.

Out of 49 patients, 45 patients $(91.83 \%)$ presented with ruptured ectopic pregnancy, $2(4.08 \%)$ had unruptured ectopic and 2 patients $(4.08 \%)$ had tubal abortion at the time of surgery.

In this study group, 38 patients were managed by salpingectomy $(77.55 \%)$, followed by salpingooophorectomy in $8(16.32 \%)$ patients. Oopherectomy was done in $2(4.08 \%)$. Fimbriectomy was done in one (2.04\%) patient (Table 2).

Table 2: Procedure done for ectopic pregnancy.

\begin{tabular}{|lll|}
\hline Procedure & $\mathrm{n} / \mathrm{t}$ & $\%$ \\
\hline Salpingectomy & $38 / 49$ & 77.55 \\
\hline Salpingo-oopherectomy & $8 / 49$ & 16.32 \\
\hline Oopherectomy & $2 / 49$ & 4.08 \\
\hline Fimbriectomy & $1 / 49$ & 2.04 \\
\hline
\end{tabular}

Out of 49 patients, 4 patients were treated laparoscopically by salpingectomy in 3 patients, salpingo-oopherectomy in one patient.

In our study, out of 50 patients, $49(98 \%)$ patients required blood transfusions and one $(2 \%)$ women did not require any transfusion.

\section{Morbidity}

In our study group about morbidity, 48 cases post operative period was uneventful, $2(4 \%)$ cases were admitted in ICU. She was managed successfully by single dose MTX. Her $\beta$-hCG level came to pre-pregnancy level $(<5 \mathrm{mIU} / \mathrm{mL})$ and USG showed complete resolution of ectopic by $2^{\text {nd }}-4^{\text {th }}$ week during follow up.

\section{DISCUSSION}

In the present study group, medical therapy was given in one $(2 \%)$ patient. $^{7}$ Ectopic pregnancies with sac measuring less than $3.5 \mathrm{cms}$, absence of fetal cardiac activity, and those with hCG levels lesser than 3,000 $\mathrm{mIU} / \mathrm{mL}$ were taken as inclusion criteria for medical therapy.

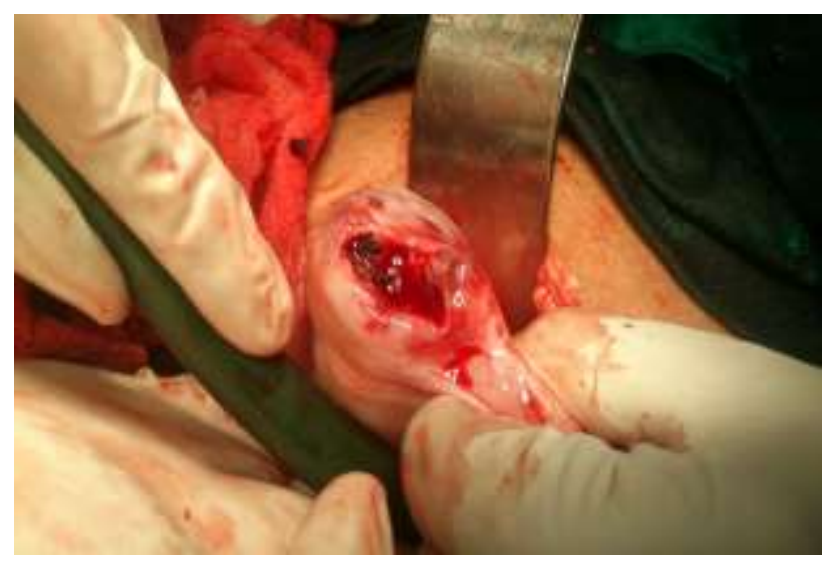

Figure 1: Ruptured cornual pregnancy.

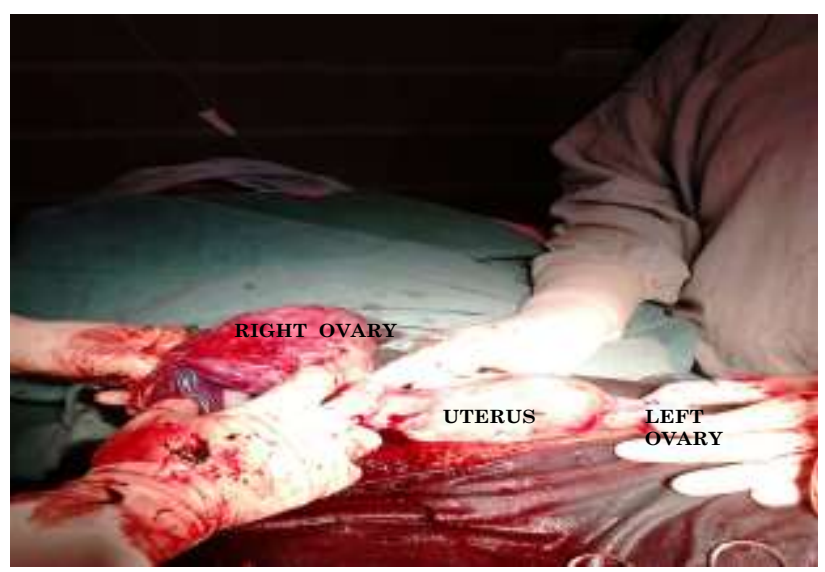

Figure 2: Ovarian pregnancy.

In the present study group, hemoperitoneum was present in $97.95 \%$ of the cases which is close to the study done by Shrestha et al $(87.5 \%){ }^{8}$ Massive hemoperitoneum of about 2000-2500 $\mathrm{ml}$ was present in 4 cases.

On laparotomy ectopic pregnancy was present on right side in $51.02 \%$ of the patients which correlates with the studies done by Kopani et al (56.2\%) and Etuknwa Bassey Tom et al (51.4\%). ${ }^{9,10}$ The right sided preponderance was due to sub-clinical appendicitis.

In the present study group, $4(8 \%)$ patients underwent laparoscopy which is minimally invasive and is the gold standard for diagnosing ectopic pregnancy.

Ectopic pregnancy in ampulla was present in $71.42 \%$ of the cases which correlates with the study done by Poonam et al (62.6\%). ${ }^{11}$ Most of the studies show 
ampulla as the common site for ectopic pregnancy. This may be because fertilization occurs in the ampullary region. Ampulla has numerous plica and these plica agglutinate due to PID leading to entrapment of zygote. Isthmic pregnancy was seen in $12.24 \%$ of the cases, interstitial pregnancy in $2.02 \%$. Ovarian pregnancy was diagnosed in $10.20 \%$ of the cases.

In the present study, $91.83 \%$ of the cases had ruptured ectopic and is correlating with the study done by Yakasai et al $(86.14 \%){ }^{15} 4.08 \%$ of the patients had un-ruptured ectopic. Tubal abortion was noted in $4.08 \%$ cases.

In the present study group, depending on hemodynamic stability and patients wish to retain fertility, various procedures were done by laparotomy and laparoscopically. Salpingectomy was done in $77.55 \%$ of the patients which is close to the study done by Poonam et al $(69.3 \%)$ as most of the cases were with ruptured ectopic. $^{11}$ Salpingo-oophorectomy, fimbriectomy was done in $10.24 \%, 4.08 \%$ respectively which correlates with the study done by Rashmi A Gaddagi et al. ${ }^{15}$

In the present study group, post-operative period was uneven full in $95.91 \%$ of cases, $4.08 \%$ were admitted to MICU due to complications of acute blood loss, acute renal failure and recovered well. $98 \%$ of the patients received blood transfusions for correcting blood loss. No case of mortality was registered during the study period.

\section{CONCLUSION}

Ectopic pregnancy is the commonest cause of pregnancy related deaths in the first trimester. Worldwide there is an increased incidence over the past three decades accounting for $1.8-2 \%$ of all pregnancies.

High index of suspicion is necessary for early diagnosis before its rupture as it gives an opportunity for conservative treatment. Early diagnosis and prompt conservative surgical or medical management not only reduces maternal morbidity and mortality but also helps in preserving fertility.

Funding: No funding sources Conflict of interest: None declared

Ethical approval: The study was approved by the Institutional Ethics Committee

\section{REFERENCES}

1. Gary CF, Leveno KJ, Bloom SL, Hauth JC, Rouse DJ, Spong CY. Williams Obstetrics. $23^{\text {rd }}$ edition, by The Mc Grew-Hill Companies; Chapter 10, Ectopic pregnancy. 2010:238-254.
2. Barnhart K, Mennuti M, Benjamin J. Prompt diagnosis of ectopic pregnancy in an emergency department setting. Obstet Gynecol. 1994;84:1010.

3. Barnhart K, Esposito M, Coutifaris C. An update on the medical treatment of ectopic pregnancy. Obstet Gynecol Clin North Am. 2000;27:653-67.

4. Kadar N. Early recourse to laparoscopy in the management of suspected ectopic pregnancy. Accuracy and morbidity. J Reprod Med. 1990;35:1153-6.

5. Samuelsson S, Sjovall A. Laparoscopy in suspected ectopic pregnancy. Acta Obstet Gynecol Scand. 1972;51:31-5.

6. Chotiner HC. Nonsurgical management of ectopic pregnancy associated with severe hyper stimulation syndrome. Obstet Gynecol. 1985;66:740-3.

7. Khaleeque F, Siddiqui RI, Jafarey SN. Ectopic pregnancies: A Three year study. J Pak Med Assoc. 2001;51:240-3.

8. Shrestha J, Saha R. Comparison of laparoscopy and laparotomy in the surgical management of ectopic pregnancy. J Coll Physicians Surg Pak. 2012;22:7604.

9. Kopani F, Rrugia A, Manoku N. Ectopic pregnancy comparison of different treatments. Journal of Prenatal Medicine. 2010;4(2):30-4.

10. Etuknwa BT, Okpara AO, Imo PA, Ekandem GJ. Ectopic pregnancy: A Nigerian Urban Experience. Korean J Obstet Gynecol. 2012;55(5):309-14.

11. Poonam Y, Uprety D, Banerjee B. Ectopic Pregnancy - two years review from BPKIHS, Nepal. Kathmandu Uni Med J. 2005;3:365-9.

12. Shabab U, Hashmi HA. Different Pattern of Presentation of Ectopic Pregnancy and its Management. Journal of Surgery Pakistan (International). 2013;18(1).

13. Panchal D, Vaishnav G, Solanki K. Study of Management in Patient with Ectopic Pregnancy. NJIRM. 2011;2(3):91-4.

14. Shetty SK, Shetty AK. A clinical Study of Ectopic pregnancies in a Tertiary Care Hospital of Mangalore, India: Innovative Journal of Medical and Health Science. 2014;4(1):305-9.

15. Yakasai IA, Abdullahi J, Abubakar I. Management of ectopic pregnancy in Aminu Kano Teaching Hospital Kano Nigeria: A 3- year. Global Adv Res J Med Med Sci. 2012;1(7):181-5.

16. Gaddagi RA, Chandrashekhar AP. A Clinical Study of Ectopic Pregnancy. JCDR. 2012;6:867-9.

Cite this article as: Suseela TL, Gunakala KC. A study on management, morbidity and mortality of ectopic pregnancy attending a tertiary care centre at Rajiv Gandhi Institute of Medical Sciences General Hospital, Kadapa, Andhra Pradesh, India. Int J Reprod Contracept Obstet Gynecol 2016;5:3736-9. 